Illinois State University

ISU ReD: Research and eData

Theses and Dissertations

$5-12-2014$

\title{
Clinician Interest in Working in Substance Abuse Treatment: The Role of Self-Efficacy, Outcome Expectancies, and Stigma
}

Genevieve Anne Covert

Illinois State University, gacover@ilstu.edu

Follow this and additional works at: https://ir.library.illinoisstate.edu/etd

Part of the Psychology Commons

\section{Recommended Citation}

Covert, Genevieve Anne, "Clinician Interest in Working in Substance Abuse Treatment: The Role of SelfEfficacy, Outcome Expectancies, and Stigma" (2014). Theses and Dissertations. 188.

https://ir.library.illinoisstate.edu/etd/188

This Thesis is brought to you for free and open access by ISU ReD: Research and eData. It has been accepted for inclusion in Theses and Dissertations by an authorized administrator of ISU ReD: Research and eData. For more information, please contact ISUReD@ilstu.edu. 


\title{
CLINICIAN INTEREST IN WORKING IN SUBSTANCE ABUSE TREATMENT: THE ROLE OF SELF-EFFICACY, OUTCOME EXPECTANCIES, AND STIGMA
}

\author{
Genevieve A. Covert
}

65 Pages

August 2014

Social Cognitive Career Theory (SCCT; Lent, Brown, \& Hackett, 1994) was used to examine clinician career interest for working in substance abuse treatment. The study examined the impact that self-efficacy and outcome expectancies have while exploring stigma as a moderating variable. Participants $(N=153)$ with experience providing mental health treatment completed the study. Self-report surveys were administered electronically. In particular Likert scales were used to assess career interests, selfefficacy, outcome expectancies, and stigma. A service-load measure and demographics survey were also completed. Correlation and regression analyses revealed that selfefficacy and outcome expectancies significantly predicted career interest in substance abuse counseling. These results were consistent with SCCT's postulates. Stigma was not significantly related to the other variables in any of the analyses. 
CLINICIAN INTEREST IN WORKING IN SUBSTANCE ABUSE TREATMENT:

THE ROLE OF SELF-EFFICACY, OUTCOME

EXPECTANCIES, AND STIGMA

GENEVIEVE A. COVERT

A Thesis Submitted in Partial

Fulfillment of the Requirements for the Degree of

MASTER OF SCIENCE

Department of Psychology

ILLINOIS STATE UNIVERSITY

2014 
CLINICIAN INTEREST IN WORKING IN SUSBTANCE ABUSE TREATMENT:

THE ROLE OF SELF-EFFICACY, OUTCOME

EXPECTANCIES, AND STIGMA

GENEVIEVE A. COVERT

COMMITTEE MEMBERS:

Jeffrey Kahn, Chair

Margaret Nauta 


\section{CONTENTS}

Page

CONTENTS $\quad$ i

$\begin{array}{ll}\text { TABLES } & \text { iii }\end{array}$

CHAPTER

I. INTRODUCTION 1

Hypotheses $\quad 3$

Methodology 4

II. REVIEW OF THE LITERATURE 5

Definitions of Substance Abuse $\quad 5$

Strategies in Substance Abuse Treatment $\quad 7$

The Service Gap for Substance

Abuse $\quad 11$

$\begin{array}{ll}\text { Social Cognitive Career Theory } & 13\end{array}$

Self-Efficacy 13

Outcome Expectations $\quad 15$

Career Interests $\quad 15$

Empirical Support for SCCT 16

SCCT and Clinician Interests 18

$\begin{array}{ll}\text { Stigma } & 20\end{array}$

$\begin{array}{ll}\text { The Present Study } & 24\end{array}$

$\begin{array}{ll}\text { III. METHOD } & 27\end{array}$

$\begin{array}{ll}\text { Participants } & 27\end{array}$

$\begin{array}{ll}\text { Measures } & 28\end{array}$

Interest in Substance-Abuse Counseling 28

Self-Efficacy with Respect to Substance-

Abuse Counseling $\quad 29$ 
Outcome-Expectancies with Respect to Working with Substance-Abusing Clients

Procedure

IV. RESULTS 33

$\begin{array}{ll}\text { V. DISCUSSION } & 40\end{array}$

Limitations and Future Research 43

Implications $\quad 46$

$\begin{array}{ll}\text { REFERENCES } & 49\end{array}$

APPENDIX A: Interest Questionnaire 53

APPENDIX B: $\quad$ Self-Efficacy Measure $\quad 55$

APPENDIX C: $\quad$ Outcome Expectancies Measure 57

APPENDIX D: $\quad$ Demographic Items 58

$\begin{array}{lll}\text { APPENDIX E: } & \text { Service-Load Measure } & 60\end{array}$

APPENDIX F: $\quad$ Recruitment Email $\quad 61$

APPENDIX G: Informed Consent Document 62

APPENDIX H: $\quad$ Study Debriefing $\quad 64$ 


\section{TABLES}

$\begin{array}{lll}\text { Table Page } & \text { Pan }\end{array}$

1. Means and Standard Deviations for Career Interests, Self-Efficacy, Outcome Expectancies, and Stigma $(\mathrm{N}=153)$

2. Means for Career Interest Items $(N=153)$

3. Intercorrelations among Career Interests, Self-Efficacy, Outcome Expectancies, and Stigma $(\mathrm{N}=153)$

4. Coefficients from the Hierarchical Regression Analysis of Self-Efficacy and Stigma (N=153)

5. Coefficients from the Hierarchical Regression Analysis of Outcome Expectancies and Stigma ( $\mathrm{N}=153)$

6. Coefficients from the Regression Analysis of Self-Efficacy and Outcome Expectancies $(\mathrm{N}=153)$ 


\section{CHAPTER I}

\section{INTRODUCTION}

Substance abuse is a serious mental health disorder that impacts millions of people worldwide every year. Since 2002 the United States has seen a fairly consistent annual prevalence rate of approximately 22.2 million people suffering from substance abuse or dependence (Substance Abuse and Mental Health Services Administration [SAMHSA], 2009). In 2009, 7.8\% of the U.S. population aged 12 years or older was diagnosed as having alcohol abuse or dependence. According to the World Health Organization (2010), global prevalence rates for alcohol use disorders are estimated to be 76.3 million people, and at least 15.3 million people have drug use disorders.

The high prevalence rate of substance abuse disorders is alarming due to the negative impact on life functioning associated with these disorders (Najavits \& Weiss, 1994). There is evidence to suggest that individuals with substance abuse disorders are underserved by clinicians. The National Survey on Drug Use and Health (NSDUH) examined the types of treatment services received by clients with comorbid disorders (SAMHSA, 2005a). According to the NSDUH, 34.2\% received strictly mental health services, $1.9 \%$ received strictly substance abuse treatment, and $11.8 \%$ received a combination of mental health and substance abuse treatment services. Research suggests that substance abuse disorders may be an undertreated cluster of disorders with only approximately $13 \%$ of individuals with comorbid disorders receiving any treatment. And 
according to the American Psychological Association, substance abuse disorders were identified as a mental health concern in $48.8 \%$ of the surveyed cases. However, in only $20.4 \%$ of cases was substance usage identified as the primary focus of therapy (Michalski et al., 2010). These studies indicate that substance abuse is not treated with the same prevalence as mental health disorders; however, there is no clear explanation for why this discrepancy exists. More research is needed to identify the factors that affect professionals' opinions regarding treatment of people who abuse substances.

Professionals develop specific interests during the course of their training and time spent working with various populations. Research has suggested that psychological professionals demonstrate an increase in negative feelings over the course of therapy when working with people who abuse substances, with the exception of 12-step drug counselors (Najavits et. al, 1995). These negative feelings may indicate that psychological professionals may be disinclined to work with people who abuse substances. Also, therapist anxiety has been identified as negatively impacting treatment effectiveness when working specifically with people who abuse substances (Najavits \& Weiss, 1994). Craig (1985) suggests that people who abuse substances have high dropout rates and are characterized as having high emotional reactions compared to other clientele. These factors may influence psychological professionals' interest in working with a clinical population characterized as being "difficult to engage in treatment until abstinence is obtained" (Najavits \& Weiss, 1994, p. 679).

Substance abuse has been characterized as the most stigmatizing mental health concern by both health professionals and society (White, 2009). Corrigan et al. (2006) wrote that "there is no physical or psychiatric condition more associated with social 
disapproval and discrimination than alcohol and/or other drug dependence" (p. 239). People who abuse substances commonly report feeling stigmatized and degraded by service providers, which consequently leads to either total avoidance of treatment seeking or prematurely dropping out of treatment (Ahern et al., 2007; Luoma, et al., 2007). Previous studies have asserted that stigma towards addiction exists (Corrigan et al., 2006; White, 2009), but the relation between career interests of clinicians and perceptions of stigma has received no attention thus far in the literature.

The primary purpose of this study was to examine the relation between mental health professionals' views on stigma and their interest in working with people who abuse substances. This study examined the relation between professionals' self-efficacy to treat those who abuse substances and their interests in working with those who abuse substances as well as the relation between professionals' outcome expectancies of working with individuals who abuse substances and their interests in working with that clientele. Self-efficacy is described as an individual's perceptions of her or his ability to accomplish tasks or properly perform actions (Bandura, 1977, 1986). Outcome expectations refer to an individual's beliefs that if she or he performs a specific behavior, then a prescribed outcome will occur (Hackett \& Betz, 1981). Furthermore, this study examined any interaction effects that occurred between professionals' views on stigma and their self-efficacy, as well as any interaction effects that occurred between professionals' views on stigma and their outcome expectancies.

\section{Hypotheses}

One hypothesis was that the positive relation between self-efficacy for working with people who abuse substances and interest in working with people who abuse 
substances would be weakened as stigma towards those who abuse substances increased. The other hypothesis was that the positive relation between outcomes expectancies for working with people who abuse substances and interest in working with people who abuse substances would be weakened as stigma towards those who abuse substances increased.

\section{Methodology}

To answer these research questions, mental health professionals were asked to complete an electronic survey. This survey asked for demographic information. There were also questions that assessed their career interests with respect to working with people who abuse substances, self-efficacy ratings for completing tasks that are commonly associated with substance abuse treatment, outcome expectancies for working with those who abuse substances, and stigma towards substance abuse. 


\section{CHAPTER II}

\section{REVIEW OF THE LITERATURE \\ Definitions of Substance Abuse}

The current Diagnostic and Statistical Manual of Mental Disorders (DSM-5;

American Psychiatric Association [APA], 2013) includes a classification for a substanceuse disorder. Substance-related concerns include a wide array of symptoms that determine the severity of the disorder. The severity of the disorder provides a reference for a counselor to gauge appropriate interventions. An important characteristic of the DSM-5 system is that the specific substances being used by the individual are included in the diagnostic code. There are ten classes of substances that are currently included in the substance use disorder: alcohol, caffeine, cannabis, hallucinogens, inhalants, opioids, sedatives, stimulants, tobacco, and other.

The DSM-5 defines a substance use disorder as "a cluster of cognitive, behavioral, and physiological symptoms indicating that the individual continues using the substance despite significant substance-related problems" (APA, 2013, p. 481). The diagnosis consists of 11 different criteria, though withdrawal is a criterion that is not included when discussing hallucinogen or inhalant use disorder. The following are descriptions of the criteria assessed when diagnosing substance use disorder. One is an inability to fulfill obligations, such as poor work performance related to substance usage or neglecting one's responsibilities as a parent, substance use in situations where it is 
physically dangerous, and social or interpersonal issues related to one's substance use, such as fights while under the influence or family concern regarding substance use.

Other symptoms include tolerance, which is defined as "a need for a markedly increased dose of a substance to achieve the desired effect; or markedly diminished effect from using the usual dose of the substance" (APA, 2013, p. 484). Withdrawal is another symptom which is "when the blood or tissue concentrations of a substance decline in an individual who had maintained prolonged heavy use of the substance" (APA, 2013, p. 484). Other symptoms include continued substance usage despite aversive physical or psychological effects, a loss of control over one's usage, a persistent want or unsuccessful attempts to control one's usage, a great amount of time being spent in activities related to obtaining, using, or recovering from the effects of the substance, and reducing time spent devoted to other areas of one's life due to one's usage. Craving is the final criterion in the diagnosis of this disorder. It is defined as "an intense desire or urge for the drug that may occur at any time but is more likely when in an environment where the drug previously was obtained or used" (p. 483). The severity of the substance use disorder is classified as mild, moderate, or severe. Severity is determined by the number of symptoms endorsed by the individual with two to three criteria considered to be mild, four to five criteria considered to be moderate, and six or more indicating severe. There are remission specifiers that indicate if any of the symptoms are currently being met and the length of time in which one has not fully met criteria. The DSM-5 also includes criteria for substance intoxication, withdrawal, and substance or medicationinduced mental disorders, which are mental health disorders that are induced by substance usage. 
The United Nations is a global entity that is charged with developing and maintaining a wide variety of initiatives for social progress. One of the prominent goal areas is to improve the quality of people's lives by promoting better living standards. The branch created to focus on health issues is the World Health Organization (WHO), which includes mental health and substance abuse issues. The WHO uses the criteria outlined in the Tenth Revision of the International Classification of Diseases and Health Problems (ICD-10) to identify problematic patterns of behavior related to substances.

The ICD-10 defines Harmful Use as "a pattern of psychoactive substance use that is causing damage to health" (WHO, 1993, p. 70). The damage to health portion includes both physical and mental health issues that are related to the substance usage. As with the DSM-5's system, the diagnosis includes specific information regarding which psychoactive substance is being used by the individual. There are diagnostic similarities between the DSM-5 and ICD-10, as both include a cluster of phenomena in which substance usage takes a higher priority than other behaviors. The WHO developed six diagnostic criteria. These include a compulsion to use a substance; difficulty managing substance-usage patterns, such as amount or frequency; physiological withdrawal when substance usage is terminated; tolerance; neglect of other pleasurable activities or interests which increases as substance usage progresses; and continued use of the substance despite harmful side effects.

\section{Strategies in Substance Abuse Treatment}

Substance abuse treatment typically involves a combination of group and individual counseling. The therapeutic goals and strategies are based on where the client is in relation to the stages of change. Prochaska and Velicer (1997) developed the stages 
of change theory to identify the processes that occur for an individual to decide and then engage in healthy behavioral changes. This theory incorporates time as an integral factor, as opposed to specifically looking at changes within an individual's behavior (Prochaska \& Velicer, 1997). According to the 2007 Treatment Episode Data Set (TEDS), approximately $56 \%$ of substance abuse treatment admissions had previously received substance abuse treatment. Approximately $22 \%$ of admissions had three or more previous substance abuse treatment episodes (SAMHSA, 2009). These figures suggest that substance abuse may be challenging to treat effectively and indicate that clinicians must develop interventions specific to clients' needs, varying from no previous treatment experiences to five or more episodes. Prochaska and Velicer's (1997) stages of change model assists counselors in identifying appropriate treatment strategies.

A large portion of clients seeking treatment are in the precontemplation stage (Prochaska \& Velicer, 1997). Precontemplation is characterized by the client identifying no significant consequences stemming from substance usage, and therefore motivation to change the behavior is low (SAMHSA, 2005b). When studying cigarette smoking, Prochaska and Velicer (1997) found that approximately $40 \%$ of their sample were in precontemplation stage, and therefore would not benefit from the standard actionoriented interventions. Clients in the precontemplation stage are often referred to treatment by outside parties, such as the legal system or family members (SAMHSA, 2009).

Therefore, initially the goal of counseling is to build motivation for abstinence, which Prochaska and Velicer (1997) labeled decisional balance. Decisional balance is defined as the relationship between the pros and cons for the identified behavior 
(Prochaska \& Velicer, 1997). Generally, group therapy is considered an effective treatment modality for altering the decisional balance when clients first enter substance abuse treatment services.

Group counseling is the primary form of treatment for substance abuse. Group counseling is considered particularly effective because it introduces clients to non-usingpeer support. People who abuse substances often have dysfunctional support networks, and a group setting allows the client to interact in healthier ways (SAMHSA, 2009). According to Yalom and Leszcz (2005), several therapeutic factors help to account for gains made in group therapy. In the early stage of treatment, universality is considered an essential component in building motivation for abstinence. Universality means finding commonalities with others in the group and learning that one is not alone with his or her difficulties. Another therapeutic factor utilized in early treatment is instillation of hope. New clients may become more motivated by seeing other group members effectively maintain abstinence from substance usage (SAMHSA, 2005b).

According to SAMHSA (2005b), individual counseling in the early stages of treatment is focused on developing rapport and trust. The counselor needs to develop an alliance with the client (SAMHSA, 2005b). By developing an alliance, counselors can begin to express concerns regarding the impact that substance usage may have had on the client's life. Counselors may use pros-and-cons lists to aid clients in exploring all aspects of their substance usage (SAMHSA, 2005b). If clients transition to the contemplation stage, which is characterized by ambivalence as an individual recognizes benefits to sobriety yet there are no immediate plans to stop the behavior (Prochaska \& Velicer, 1997), counselors will oftentimes use Motivation Interviewing (MI) in individual 
sessions (SAMHSA, 2005b). MI is considered to be especially effective with individuals who abuse substances because the therapeutic strategy focuses on the clients' values. Instead of counselors coercing a change of the clients' values, MI explores how abstinence from substances is a better fit with their existing values (Miller \& Rose, 2009). Oftentimes this approach strengthens the therapeutic alliance. This alliance allows counselors to address clients' denial and resistance towards changing the using behavior (SAMHSA, 2005b).

As clients progress through the stages of change, they are able to utilize process groups more effectively (SAMHSA, 2005b). Clients are able to discuss factors contributing to their substance usage and relate their experiences with others who abuse substances. When individuals develop specific plans and engage in new, healthier behaviors they have transitioned from the contemplation stage to the preparation and action stages. Preparation occurs when individuals begin developing specific plans to initiate change. This stage typically includes the reduction of usage or plans to stop substance usage in the near future. This stage leads to the action stage. Action occurs as individuals drastically reduce their substance usage and begin enacting plans for change. Individuals alter their environments and behavior patterns to allow for total abstinence or safer substance usage (SAMHSA, 2005b). In process counseling groups, clients are able to discuss their lives while learning both how to provide and receive feedback from treatment peers (SAMHSA, 2005b). When clients transition into contemplation, preparation, or action stages, the group can provide support for positive changes while also providing accountability when clients struggle to address lingering unhealthy behaviors or ambivalence in regards to future substance usage (SAMHSA, 2005b). 
Another key component of substance abuse treatment is psychoeducation. This occurs both in individual and group settings. For example, psychoeducational groups utilize the imparting information therapeutic factor (Yalom \& Leszcz, 2005). Psychoeducation covers a vast array of topics, which are geared towards developing healthier ways to interact with the environment without substances; including assertiveness training, stress management, and relapse prevention. Psychoeducation is considered essential for providing substance users with information regarding what addiction is and how to manage their daily lives without addictive substances.

\section{The Service Gap for Substance Abuse}

There is value in addressing a potential lack of treatment availability for individuals with substance abuse issues. The NSDUH (SAMHSA, 2005a) reported that in the U.S. only 1.4 million people received treatment for drug issues, and 1.5 million received treatment for alcohol issues in 2002. According to SAMHSA (2009) in 2007, almost half (44\%) of the admissions to substance abuse treatment programs, aged 16 and older, were participating in substance treatment for the first time.

The National Center on Addiction and Substance Abuse (CASA, 2001) analysis concluded that in 1998 while 5 million drug-using people would have benefitted from close access to treatment services, only approximately 2 million people received services. The Office of the National Drug Control Policy also reported that in 2001, approximately $24 \%$ of people seeking treatment for substance abuse concerns were unable to find treatment services (as cited in Center for Disease Control [CDC], 2002). CASA (2001) collected data to explore the financial impact of substance abuse on state budgets. The 2001 analysis determined that only about $5 \%$ of the money collected through taxes to 
fund social programs related to addiction was actually being spent on prevention and treatment of substance abuse. While these figures suggest that improvements have been made financially to provide more access to substance treatment, there is still a need for more availability of services. Even when individuals are motivated to address drug issues, almost one quarter were unable to establish services (SAMSHA, 2009). And only a small percentage of economic efforts to address addiction actually go towards treatment for substance abuse (CASA, 2001).

In 2008, the American Psychological Association (Michalski et al., 2010) collected demographic and service load information from its members, as well as licensed non-members and various other non-members working in a psychology health service field. According to the report, approximately $49 \%$ of service load cases involved individuals with a substance abuse diagnosis. However, only $20 \%$ of the cases were being treated primarily for the substance usage concerns (Michalski et al., 2010). Michalski et al. (2010) determined that primary substance abuse treatment accounted for only $5 \%$ of the surveyed service workers' caseloads. Despite approximately one of every two clients meeting criteria for substance abuse concerns, only $5 \%$ of service providers addressed those concerns as the primary issue. The surveys conducted by Michalski et al. (2010) and NSDUH (SAMHSA, 2005a) suggest that despite the prevalence of substance abuse issues in the U.S., there are issues with accessing resources, as well as little emphasis on substance abuse treatment. Vocational counseling provides insights into how to rectify a lack of treatment availability. 


\section{Social Cognitive Career Theory}

Vocational psychology, which explores the factors that influence people's career decisions and their ability to make career decisions, provides a literature from which hypotheses about the service gap in substance abuse treatment can be developed. In 1994 Lent, Brown, and Hackett developed a theory to explain how personal factors are related to those decisions. Social cognitive career theory (SCCT) draws from Bandura's (1977, 1986) work on self-efficacy. This theory explores how a complex set of factors intertwine to determine performance attainment. Some of these factors include selfefficacy, outcome expectations, interests, goals, and activity selection (Lent et al., 1994). For the purposes of this study, self-efficacy and interests of clinicians who could potentially treat substance-abusing clients were the factors identified for examination.

\section{Self-Efficacy}

In the context of the SCCT, self-efficacy is described as an individual's perceptions of her or his ability to accomplish tasks or properly perform actions (Bandura, 1977, 1986). Bandura postulated that self-efficacy is not based upon actual performance outcomes but merely stems from an individual's perceptions of his or her skills. He discussed that self-efficacy results from a wide range of experiences from actual performance to vicarious observations of others, physiological states to verbal persuasion. Overall, Bandura (1977) postulated that cognitive appraisals play an influential role on our desire to perform certain actions and tasks.

According to Bandura (1997), actual performance, or enactive mastery experience, occurs when an individual has performed the task or actions closely related to the task and receives corresponding feedback about his or her performance. So when 
individuals perform a behavior successfully, it strengthens their self-efficacy to perform that behavior again successfully. If individuals were able to successfully shoot a basketball into the hoop, for example, then self-efficacy for that behavior would strengthen. Typically actual performance is considered to be the strongest source of building self-efficacy (Bandura, 1997). Vicarious observation references individuals' analysis of others' success when they perform certain tasks or actions (Hackett \& Betz, 1981). An example would be an individual seeing a peer successfully shoot a basketball repeatedly into the hoop. Viewing another individual repeatedly succeed in performing a task can increase self-efficacy, despite not engaging in the behavior directly. Other methods of altering self-efficacy are physiological arousal and verbal persuasion (Bandura, 1977). Individuals' self-efficacy may strengthen if he or she experiences a decrease in physiological responses, such as those related to anxiety, when preparing to perform a task (Hackett \& Betz, 1981). An example would be individuals experiencing a decrease in the physiological responses to anxiety, such as relaxing their muscles or deepening their breathing prior to shooting the basketball. Also receiving verbal feedback of encouragement that individuals can successfully perform the task positively influences self-efficacy (Hackett \& Betz, 1981). When shooting a basketball, selfefficacy may be strengthened if people receive positive verbal cues from others. Bandura (1997) postulated that all four of these sources of feedback play a role in people's cognitive analysis of whether or not they have the skills needed to perform the task. If people perceive themselves as having many of the necessary skills to perform said task, they are much more likely to engage in that task (Bandura, 1997). 


\section{Outcome Expectations}

SCCT links self-efficacy with outcome expectations and interests. Outcome expectations refer to an individual's beliefs that if she or he performs a specific behavior, then a prescribed outcome will occur (Hackett \& Betz, 1981). Hackett and Betz (1981) described the differences between self-efficacy and outcome expectations as self-efficacy being people's beliefs regarding the ability to perform a behavior, versus a belief regarding the consequences that result from the behavior. Outcome expectations can vary widely, and they include both favorable and unfavorable outcomes that might result from engaging in a behavior. For example, a positive outcome expectation associated with choosing to become a substance abuse counselor might be that one could easily find work. A negative outcome expectation that someone might hold is that one would be doing difficult and thankless work if he or she chose to work with people who abuse substances.

\section{Career Interests}

According to Lent et al. (1994) career interests are defined as "patterns of likes, dislikes, and indifferences regarding career-relevant activities and occupations" (p. 88). The theory speculates that career interests are influenced by perceptions of abilities and outcome expectations. This means that if an individual already perceives having the skills to perform a task and then also experiences positive outcomes from performing the task, the individual develops some degree of interest related to the task (Lent et al., 2002). When an individual experiences those conditions, she or he is likely to engage in behaviors geared towards the interest areas. If an individual perceives that she or he is unable to perform a task, or that negative outcomes would result, interest in that task or 
related tasks will be decreased based on those perceptions (Lent et al., 1994). The theory also indicates that self-efficacy and outcome expectations influence an individual's goals related to activity involvement, activity selection, and performance attainments.

\section{Empirical Support for SCCT}

Essentially, SCCT postulates that self-efficacy plays a critical role in a person's decisions and purposeful, goal-directed actions. Hackett and Betz (1981) demonstrated these relations in a study which concluded that college students limited their career options based on their perceived capabilities educationally and vocationally. Sniehotta, Scholz, and Schwarzer (2005) explored the role self-efficacy plays in the initiation and maintenance of physical exercise in cardiac rehabilitation patients. As expected, selfefficacy and outcome expectancies played a very influential role in participants' intentions to engage in physical exercise. Sniehotta et al. (2005) also reported that selfefficacy independently predicted engagement in physical exercise. The study further revealed the role that maintenance self-efficacy played in the long-term self-regulatory lifestyle changes associated with routine physical exercise (Sniehotta et al. 2005).

With regard to substance abuse, Baldwin et al. (2006) developed a study to explore the role self-efficacy played in cigarette smoking cessation behaviors. People's self-efficacy played a significant role in smoking cessation at both 7 and 9 months after the completion of an intervention program. This study suggests that there are lasting effects on behaviors when individuals perceive themselves as capable of performing a task.

Another study which explored the impact of self-efficacy on behavior was conducted by Bandura, Reese, and Adams (1982). The study examined the coping 
responses in individuals with phobias, using vicarious observation of modeling to alter levels of self-efficacy. Bandura et al. determined that the levels of self-efficacy were altered based on the degree of vicarious observation. They also determined that the individuals' coping skills were congruent with self-reported levels of self-efficacy. At the conclusion of the study, all participants were able to engage in some coping skills, including participants who only observed others modeling coping behaviors for phobic stimuli. The study suggests that self-efficacy can be influenced through indirect methods, but more importantly that the coping skills strengthened as self-efficacy increased.

SCCT proposes that self-efficacy and outcome expectancies, together, lead to the development of an individual's interests. Essentially the theory posits that "people form enduring interests in activities at which they view themselves to be efficacious" (Lent et al., 1994, p. 85). Hackett and Betz's (1981) article explores this relationship based upon the relevant research findings. The article focused on the differences between men and women's career development, and the cognitive processes that ultimately dictate career decisions. The authors indicated that at the time women lacked the needed experiences to develop career interests outside of standard feminine careers (Hackett \& Betz, 1981). For instance, the article explored how women have far fewer experiences through actual performance, which is generally considered the most prominent source for strengthening self-efficacy. Therefore, career interests are limited and under-explored due to a lack of sufficient experience to truly foster self-efficacy outside of what society generally encourages through sex roles (Hackett \& Betz, 1981).

As an extension of previous research, Lent, Brown, and Larkin (1986) explored self-efficacy's connection with career interests. The study focused on self-efficacy 
expectations for undergraduates considering science or engineering majors who were enrolled in an educational planning course. The participants completed surveys measuring their self-efficacy in regards to educational requirements and academic behaviors (Lent et al., 1986). The most notable finding was that self-efficacy in regards to completing the educational requirements positively correlated with interest in science and engineering as a possible career choice (Lent et al., 1986).

In the SCCT model, the relation between self-efficacy and interests is considered to be self-efficacy leading to interests. However, it is important to consider that there is evidence to suggest a reciprocal relation between the two factors (Nauta, Kahn, Angell, \& Cantarelli, 2002). Nauta et al. (2002) examined career interests among undergraduate students at a four-year university at various intervals during the academic calendar year. Overall the study found that there appeared to be a reasonable degree of reciprocity between the two factors. These findings suggest that interests may play a motivational role. The researchers suggested that the interest-to-efficacy pathway could be the result of regular feedback in the form of classes and assignments (Nauta et al., 2002).

Extrapolating from that interpretation, this study opens the door for the possibility that feedback in the form of societal stigma could play a role in interest development or selfefficacy.

\section{SCCT and Clinician Interests}

SCCT has been used to explore a wide variety of questions regarding career interests and decision-making. The present study focused on the impact of self-efficacy and career interests on counselors' decisions to choose or avoid work with people who abuse substances. Specifically, this study examined how these factors impact counselors' 
pursuit of careers in substance abuse treatment, or even just addressing substance abuse issues as a course of treatment when addressing other psychological issues. Numerous studies (e.g., Hackett \& Betz, 1981, Lent et al., 1986) explored the connection between self-efficacy and career interests among a variety of educational and career areas, but examined choices in terms of broad occupational field choices. It is less clear if this portion of the SCCT framework is useful in accounting for people's subspecialty choices within broad occupational fields. There is no known research exploring how these concepts relate to counselors' choices to provide substance abuse treatment. Based on the indications that substance abusers are an underserved population, it is important to explore counselors' career decisions.

One exception to the lack of SCCT research involving substance-abuse clinicians was a study by Mangrum and Spence (2008). They examined differences in characteristics of counselors in mental health versus substance abuse settings when dealing with co-occurring disorders. When examining counselor characteristics, the researchers found that, despite the greater experience working with co-occurring disorders, the mental health counselors rated themselves lower on self-efficacy on important clinical areas, specifically "the disease and recovery model with parallel phases of recovery and stages of change/stages of treatment domain and the individualization of treatment principle" (Mangrum \& Spence, 2008, p. 166). Typically these concepts are associated with substance abuse treatment programs; however, these concepts are used to determine treatment planning, the use of appropriate counseling interventions, and discussing clients' progress as they transition into recovery regardless of the presenting concerns. Mangrum and Spence (2008) concluded that increased training for mental 
health counselors treating co-occurring disorders in use of stages of change and the recovery model is needed.

\section{Stigma}

Although theory and research suggest that greater self-efficacy with respect to treating substance use would be associated with greater interest in doing so, this may not necessarily be the case. This is because substance abuse treatment may be a stigmatized activity even within the mental health profession. When examining treatment of psychological disorders, mental health and substance abuse are differentiated from one another. Some studies (Gassman \& Weisner, 2005; Scott \& Wahl, 2011) suggest that, as with society in general, counselors and other community mental-health providers hold biases towards individuals experiencing psychological impairment. Some researchers have concluded that substance dependence is the presenting concern most closely associated with social condemnation and subsequent alienation (Corrigan, Watson, \& Miller, 2006).

It is important to understand the nature of society's stigma towards substance abuse as a precursor to its impact on counselors' attitudes and reactions. One of the major sources of stigma towards substance abuse issues stems from the evaluation that usage is a personal choice, such that substance usage is a voluntary action as opposed to an actual mental disorder. Corrigan, Kuwabara, and O'Shaughnessy (2009) found that the general public offers more help to people with physical disorders and traditional mental health concerns than to those with substance abuse issues. So despite substance abuse's conceptualization as a disease and its diagnostic criteria being included in the 
DSM-5 (APA, 2013) as a mental disorder, there is still a prevalent underlying belief that it is a personal choice as opposed to a disorder (White, 2009).

Scott and Wahl (2011) explored the existence of double stigma, collecting data in regards to stigma associated with both race and the issue of substance abuse. This study used interviews with African-American men with a history of substance abuse problems, to explore their experiences and perceptions of how others respond to them. In regards to substance abuse stigma, the interviewees reported that they were treated poorly due to their substance usage, which ultimately led to feelings of rejection and isolation both in their relationships and within society in general. The interviewees reported negative experiences even within substance abuse treatment facilities. One interviewee shared his reactions to stigma perceived while in substance abuse treatment: "It can get you really upset and angry and you won't do good there [in treatment]. If I stayed, I didn't take the treatment serious [sic]" (Scott \& Wahl, 2011, p. 65). Overall, the interviewees in the study expressed similar emotional reactions and discussed the ineffectiveness of treatment when they perceived the treatment providers as holding negative views towards them. Beschner and Walter`s (1985) interviews with people using heroin also revealed similar responses from their interviewees about perceiving negative attitudes from staff members.

Scott and Wahl (2011) concluded that the effectiveness of treatment is significantly disrupted when stigma is perceived within a treatment setting, based on selfreports of interviewees noting that they were less engaged and received lower outcome benefits from substance abuse treatment. One factor that has been attributed to more positive substance abuse treatment outcomes is the therapeutic alliance developed 
between the counselor and client. Crits-Christoph et al. (2009) examined the differences in effectiveness between two forms of counseling; however, the results suggested that the alliance that the counselor developed contributed more to successful treatment outcomes than did the type of counseling performed. These two studies (Crits-Christoph et al., 2009; Scott \& Wahl, 2011) both indicate that when people who abuse substances perceive stigma or negative views by substance abuse treatment providers, the effectiveness of the therapeutic outcomes appears to decrease.

It also appears that counselors and community mental-health providers' perceptions may differ when treating mental health versus substance abuse issues. Questions regarding negative perceptions and feelings towards individuals with psychological disorders have led to research into possible stigma. Servais and Saunders (2007) explored clinical psychologists' perceptions of individuals with various mental illnesses. The study asked clinical psychologists to rate "the effectiveness, understandability, safety, worthiness, desirability, and similarity of persons with moderate depression, borderline features, and schizophrenia" (Servais \& Saunders, 2007, p. 215). The researchers concluded that the psychologists did indeed hold negative perceptions of clients with schizophrenia and borderline features. This includes approximately half of the respondents reporting that individuals with borderline features are undesirable and three-quarters reporting feeling very dissimilar from individuals with schizophrenia (Servais \& Saunders, 2007). This study raised concerns in regards to "such perceptions inhibiting the therapist's ability to display empathy and genuine concern" (Servais \& Saunders, 2007, p. 218). 
Another study (Najavits et al., 1995) focused on the emotional reactions of counselors towards people who use substances. The counselors endorsed concerns related to the degree to which they were performing therapeutic interventions effectively and appropriately, as well as concerns over the relationship with the client. The findings suggest that counselors are concerned about disagreements or problematic relationships with clients who use substances, despite a lack of evidence to substantiate this concern (Najavits et al., 1995). The authors speculated that these emotional reactions may alter a counselor's effectiveness in rendering therapeutic interventions.

Other studies have specifically focused on negative attitudes towards people who use substances. McLaughlin and Long (1996) asserted that many of the negative perceptions found in the counseling and helping community stem from personal experiences with those who use substances, as opposed to being directed by professional training or education. Gassman and Weisner (2005) further explored how community providers viewed alcohol and drug problems. Their study noted that the providers differentiated between alcohol versus drug issues, such that providers typically viewed drug issues as more severe and commonly associated drug usage with criminal behavior (Gassman \& Weisner, 2005). They also reported that many providers view drug issues as a social problem, and therefore they commonly received punitive stances and treatment from providers. Alcohol, on the other hand, was viewed primarily as a genetic disorder, and therefore those clients received more supportive responses (Gassman \& Weisner, 2005).

Luoma et al. (2007) explored the role of stigma towards individuals involved in substance abuse treatment. This study explored three forms of stigma and the potential 
impact this stigma has on treatment. They enumerated three types of stigma: enacted, which is first-hand experienced discrimination; perceived, which refers to how individuals in a stigmatized group view societal stigma; and self, which describes one's own negative thoughts, behaviors, and emotions associated with membership in a stigmatized group (Link, Yang, Phelan, \& Collins, 2004). The majority of the participants endorsed the perception that most people hold stigmatizing beliefs regarding people who abuse substances. This study focused less on whether or not the participants perceived stigma from the treatment facility staff. However, Luoma et al. discussed that stigma plays a prominent role in the interactions of people who use substances with society in general. Because research suggests that stigma is relevant to how people who use substances view themselves and others' perceptions of them, it is an important area to address in substance abuse treatment. By not addressing this concern, it may appear that counselors are demonstrating passive, or indirect, acceptance of society's negative views, which may hinder substance users' progress in treatment programs.

\section{The Present Study}

There is a discrepancy between individuals in need of substance abuse treatment and the availability of that treatment service. There also appears to be limited research into the role that self-efficacy, outcome expectancies, and interests play in counselors' decisions to work with substance users. Also, little research exists examining the presence of stigma amongst practitioners in the helping professions towards people who use substances. This study explored the role that self-efficacy, outcome expectancies, and interests play in counselors' career decision-making for working with people who use substances, and as it also explored whether stigma is a moderating factor that influenced 
the decision-making process of those in the counseling profession. This study aimed to provide valuable exploratory information to rectify the lack of services available to those suffering with substance abuse issues.

I hypothesized that there would be a positive relation between self-efficacy for working with people who abuse substances and interest in working with those who abuse substances. Also, I expected that there would be a positive relation between outcome expectancies for working with those who abuse substances and interest in working with those who abuse substances. However, I also hypothesized that when counselors held strong stigma towards those who abuse substances, the relation between interest and selfefficacy would be very weak. The hypothesis was intended to establish that stigma interrupted the relation between self-efficacy and stigma. Stigma held a stronger influence over career interests, so that even when counselors held high efficacy beliefs they chose other career interests if they held negative feelings towards those who use substances. I also hypothesized that when counselors held strong stigma towards those who abuse substances, the relation between outcome expectancies and interest would be very weak. This hypothesis was intended to establish that even when a counselor held positive beliefs about the consequences of providing substance abuse treatment, if they held negative beliefs regarding those who abuse substances then their career interest was lower. For counselors who did not hold strong stigma towards people who abuse substances, I expected the efficacy-interest relation would be positive and very strong. Also for counselors who did not hold strong stigma towards people who abuse, I expected the expectancies-interest relation would be positive and strong. Therefore, I 
hypothesized that there would be an interaction between self-efficacy and stigma and an interaction between outcome expectancies and stigma. 


\section{CHAPTER III}

\section{METHOD}

\section{Participants}

Professionals with counseling-related educational experiences and occupations were recruited with the assistance of seven state counseling associations. Only individuals with counseling-related work experience were included since in this study I aimed to examine individuals who had made career decisions and worked directly with clients. The sample included 153 participants from diverse backgrounds in counseling education. The sample primarily consisted of professionals with Master's degree education levels (80\%). There were 7 participants with Ph.D.s (5\%), 11 with Bachelor degrees (7\%), 1 with a Psy.D. (1\%), and 11 with other degrees, which were primarily reported at Ed.S (7\%). The sample consisted of 130 women (85\%), 21 men (14\%), and 2 participants who did not identify their gender (1\%). In terms of ethnicity the sample included 106 European Americans (69\%), 29 African-Americans (19\%), 6 Latino/Latinas (4\%), 6 Asian-Americans (4\%), 2 biracial or multiracial individuals (1\%), and 4 people who did not indicate their ethnicity $(3 \%)$.

The majority of the participants reported obtaining licensure in at least one of the following fields: psychology, social work, counseling, medicine, family therapy, or other. Some of the self-reported licensures were addictions, pastoral, education, and art therapist. The majority of the participants reported licensure in one domain $(n=98$, 64\%), 3 participants reporting having two licenses (2\%), 46 were unlicensed (30\%), and 
6 did not report their licensure status (4\%). Participants' counseling experiences varied from 6 months to 40 years. In regards to theoretical orientation, the most frequently endorsed was eclectic at $29 \%$ and cognitive at $25 \%$. Other orientations selected include behavioral, family systems, humanistic/existential, psychodynamic, Adlerian, solutionfocused, reality, and cognitive-behavioral. Thirteen participants (8\%) provided no response regarding their theoretical orientation.

Participant responses indicated a diverse group of occupational settings including private practice (19\%), community mental health centers (18\%), university counseling centers $(8 \%)$, child/adolescent/family guidance centers $(6 \%)$, psychiatric medical groups (4\%), general medical centers (1\%), and Veterans' Affairs (VA) medical center (1\%). Sixty-six participants (43\%) provided occupational settings in an open-ended format, which included settings such as schools, in-patient programs, substance abuse, and correctional facilities. Participation in the study was voluntary, though participants were eligible to win a $\$ 25$ gift card.

\section{Measures}

A series of Likert scales was used to assess self-efficacy, interest, outcome expectancies, and stigma related to substance abuse treatment provision. These are described below.

\section{Interest in Substance-Abuse Counseling}

To determine interest in working with substance-abusing clients, a list of 38 items was developed by the author that covered a variety of common client concerns when seeking counseling. Of the 38 items, 4 items were included to measure substance abuse: Alcohol Abuse, Addictions, Drug Abuse, and Substance Abuse. The measure asked 
participants to indicate their level of interest in treating each concern on the 38 -item list (Appendix A). The measure used a 5-point Likert scale with 1 indicating no interest and 5 indicating strong interest. Level of interest was calculated by averaging the scores of the 4 items related to chemical dependency treatment. Coefficient alpha for interest scores was .98 .

\section{Self-Efficacy with Respect to Substance-Abuse Counseling}

The self-efficacy scale, also developed by the author for this study, was modeled on the interest measure (Appendix B). The measure asked the participants to rate their confidence for delivering effective counseling for a variety of counseling concerns. The same 38-item list was used, as well as the same 4 items that were used to calculate interest. This measure also used a 5-point Likert scale with 1 indicating no confidence and 5 indicating strong confidence. The reported scores on the 4 substance-abuse items were averaged to determine the participants' degree of self-efficacy with respect to treating substance-abusing clients. Coefficient alpha for efficacy scores was .97.

\section{Outcome Expectancies with Respect to Working with Substance-Abusing Clients}

To assess the outcome expectancies of participants, the author of this study developed a questionnaire consisting of 10 statements (Appendix C). The measure asked participants to rate their agreement regarding beliefs about the potential consequences of working with people who abuse substances using a similar format in previous research (Leigh \& Stacy, 1993). This measure included 5 statements that reported positive consequences for working with those who abuse substances and 5 statements that reported negative consequences for working with that clientele. This researcher 
developed the statements based on possible consequences that may occur from working with individuals who abuse substances.

This measure also used a 5-point Likert scale with 1 indicating strongly disagree and 5 indicating strongly agree. To score the measure, the positively worded questions were summed to create an overall score. Total possible scores ranged from 5 to 25 with higher scores corresponding to more positive expected consequences for working with people who abuse substances. This score determined the participants' outcome expectancies with respect to treating substance-abusing clients. When examining the data, I found that the 5 reverse-scored items contributed to a low alpha; therefore only the 5 positively worded items were used. Coefficient alpha for outcome-expectation scores was .69 .

\section{Stigma towards Substance Abuse}

Luoma et al. (2010) developed a stigma measure to assess perceived stigma towards those involved in substance abuse treatment. The measure was adapted from one previously developed to assess perceived stigma towards individuals with serious mental illnesses. Luoma et al.'s (2010) measure is called the Perceived Stigma of Addiction Scale (PSAS). The PSAS was comprised of 8 items, using a 7-point Likert scale with 1 indicating strongly disagree and 7 indicating strongly agree. The PSAS was scored by creating a single total of the summation of the responses. Items $1,2,3,4,6$, and 8 were reversed scored. The score ranges from 8 to 32 with higher scores indicating a higher degree of perceived stigma in the respondent. The coefficient alpha from this study was .73, which was consistent with previous findings (Luoma et al., 2010). 


\section{Additional Measures}

Two additional sets of questions were included in the study. The first was a demographic survey (Appendix D), which gathered information regarding theoretical orientation and current working environment. The last survey gathered information regarding the amount of time the participants engaged in counseling clients on a variety of counseling concerns (Appendix E). The scale used a 5-point Likert scale with 1 indicating no time and 5 indicating all of their time focused on treating the counseling concern. These questionnaires provided data to describe the sample in greater depth. Respondents who reported often or all for specific concern areas most frequently indicated the following treatment areas: anxiety (63\%), depression (55\%), and family concerns $(54 \%)$. In regards to alcohol abuse $49 \%$ reported treating no clients and for other substance abuse $47 \%$ reported treating no clients in the past 60 days.

\section{Procedure}

A preliminary email was sent to 38 state counseling associations in the United States to determine the feasibility of recruiting participants via their organizations. These 38 states readily provided the general association's contact email address on the association website. The email requested that each state association distribute information regarding the study to its members requesting their participation in the study. Seven associations agreed to distribute information. Four state associations (Alabama, Alaska, Louisiana, and Maryland) distributed the solicitation email using their listserv. New York and Minnesota posted the information on Facebook and LinkedIn website pages. North Dakota distributed the information in their association's March, 2014 newsletter. 
A solicitation letter was distributed to potential participants (Appendix F). Interested professionals clicked on a link which directed them to the survey web page. There, participants first provided informed consent (Appendix G). I emphasized that participation in the study was voluntary, but for their participation each individual could elect to be entered into a random drawing for a $\$ 25$ gift card. Participants completed the career interest scale, the self-efficacy scale, the service load measure, the outcome expectancies scale, the PSAS, and the demographic survey. When they finished, they read a short debriefing statement (Appendix H), and then they had an opportunity to provide an email address to be entered into the raffle. 


\section{CHAPTER IV}

\section{RESULTS}

Means and standard deviations were calculated for each of the tested variables

(see Table 1). The mean of each career interest item was also calculated and determined that the four substance-related items were ranked 29-32 on the interest list (see Table 2). Correlations determined the strength and direction of the relations between each of the variables (see Table 3). Self-efficacy and interest had a very large effect correlation (Cohen, J., 1992). A medium effect correlation was found between outcome expectancies and interest, and between self-efficacy and outcome expectancies. The correlations revealed that stigma was unrelated to the other variables.

Table 1

Means and Standard Deviations for Career Interests, Self-Efficacy, Outcome Expectancies, and Stigma $(N=153)$

\begin{tabular}{lcc}
\hline Measure & $M$ & $S D$ \\
\hline Career Interest & 10.79 & 5.40 \\
Self-Efficacy & 11.26 & 5.26 \\
Outcome Expectancies & 17.29 & 3.16 \\
Stigma & 19.98 & 2.88 \\
\hline
\end{tabular}


Table 2

Means for Career Interest Items $(N=153)$

\begin{tabular}{|c|c|}
\hline Item & $M$ \\
\hline Stress & 4.20 \\
\hline Coping Behavior & 4.19 \\
\hline Self-Esteem & 4.18 \\
\hline Decision-Making & 4.18 \\
\hline Anxiety & 4.01 \\
\hline Depression & 3.87 \\
\hline Parent-Child Relationships & 3.86 \\
\hline Grief \& Loss & 3.76 \\
\hline Trauma & 3.61 \\
\hline Post-Traumatic Stress Disorder (PTSD) & 3.60 \\
\hline Religion/Spirituality/Values & 3.52 \\
\hline Anger & 3.48 \\
\hline Academic Achievement & 3.45 \\
\hline College Student Development & 3.40 \\
\hline Romantic Relationship Concerns & 3.40 \\
\hline Perfectionism & 3.36 \\
\hline Career Development & 3.28 \\
\hline Marital Conflict & 3.24 \\
\hline Abuse (Adult Survivors) & 3.22 \\
\hline Suicide & 3.14 \\
\hline
\end{tabular}


Table 2 Cont.

\begin{tabular}{|c|c|}
\hline Ethnic/Racial Identity & 3.14 \\
\hline Child Abuse & 3.11 \\
\hline Gender Roles/Identity & 3.11 \\
\hline Developmental Issues & 3.09 \\
\hline Victimization/Incest/Rape & 3.07 \\
\hline Sexual Preference Issues & 3.00 \\
\hline Sexual Abuse (child victims) & 2.93 \\
\hline Obsessive Compulsive Disorder (OCD) & 2.87 \\
\hline Addictions & 2.77 \\
\hline Alcohol Abuse & 2.72 \\
\hline Substance Abuse & 2.65 \\
\hline Drug Abuse & 2.64 \\
\hline Eating Disorder & 2.62 \\
\hline Cancer & 2.53 \\
\hline HIV/AIDS & 2.48 \\
\hline Borderline Personality Disorder (BPD) & 2.47 \\
\hline Schizophrenia & 2.46 \\
\hline Autism & 2.36 \\
\hline
\end{tabular}


Table 3

Intercorrelations among Career Interests, Self-Efficacy, Outcome Expectancies, and Stigma $(N=153)$

\begin{tabular}{lcccc} 
Measure & 1 & 2 & 3 & 4 \\
\hline 1. Career Interest & -- & & & \\
2. Self-Efficacy & $.76^{* * *}$ & -- & -- & \\
3. Outcome & $.38^{* *}$ & $.34^{* *}$ & & - \\
Expectancies & & & .10 & \\
4. Stigma & .00 & .10 & &
\end{tabular}

$* p<.05 ; * * p<.01 ; * * * p<.001$

To test the hypotheses about moderation, moderation analyses using multiple regression were performed. For the first analysis, self-efficacy was identified as the independent variable. Career interest was identified as the dependent variable, in congruence with SCCT. The moderator variable was stigma. As you can see in Table 4, in Step 1 self-efficacy had a highly significant beta weight, suggesting that higher selfefficacy with respect to substance-abuse counseling was predictive of higher interests in doing substance-abuse counseling. Stigma did not have a significant beta weight. In Step 2, the interaction term between self-efficacy and stigma was nonsignificant. The interaction term did not increase $R^{2}, \Delta R^{2}=.00, F(1,149)=0.02, p=.88$. Thus, selfefficacy was statistically significantly related to career interest. Stigma did not have a statistically significant impact on the positive relation between self-efficacy and career interest. These results indicate that self-efficacy is a significant predictor of career interest, when controlling for the influence of stigma. 
Table 4

Coefficients from the Hierarchical Regression Analysis of Self-Efficacy and Stigma $(N=$ 153)

\begin{tabular}{lcccc}
\hline Step and variable & $B$ & $S E B$ & $\beta$ & $R^{2}$ \\
\hline Step 1 & .79 & .05 & $.77 * * *$ & \\
Self-Efficacy & -.14 & .10 & -.07 & \\
Stigma & & & & .59 \\
Step 2 & .74 & .35 & $.72 *$ & \\
Self-Efficacy & -.17 & .23 & -.09 & \\
Stigma & .00 & .02 & .06 & \\
Self-Efficacy x Stigma & & &
\end{tabular}

For the analysis of outcome expectancies, a second moderation analysis using multiple regression was performed. Outcome expectancies were identified as the independent variable. Career interest was identified as the dependent variable, in congruence with SCCT. The moderator variable was stigma. As you can see in Table 5, in Step 1 outcome expectancies had a significant beta weight. Stigma did not have a significant beta weight. In Step 2, the interaction term between outcome expectancies and stigma was found to be nonsignificant. The interaction term did not increase $R^{2}, \Delta R^{2}=$ $.01, F(1,149)=0.81, p=.37$. Outcome expectancies were statistically significantly related to career interest. Stigma did not have a statistically significant impact on the positive relation between outcome expectancies and career interest. These results indicate 
that outcome expectancies are a significant predictor of career interest, when controlling for the influence of stigma.

Table 5

Coefficients from the Hierarchical Regression Analysis of Outcome Expectancies and Stigma $(N=153)$

Step and variable

$\begin{array}{llll}B & S E B & \beta & R^{2}\end{array}$

Step 1

Outcome Expectancies

.66

.13

.15

Stigma

$-.08$

.14

Step 2

Outcome Expectancies

Stigma

Outcome Expectancies x Stigma
1.5

.69

$-.04$
.95

.86

.05
$.39 * * *$

$-.04$

$* p<.05 ; * * p<.01 ; * * * p<.001$.

A follow-up regression analysis was conducted to explore the relation between self-efficacy and outcome expectancies. This analysis was performed in order to determine whether self-efficacy and outcome expectations overlapped in their prediction of interests. As you can see in Table 6, both self-efficacy and outcome expectancies had significant beta weights. Self-efficacy was statistically significantly related to career interest. Outcome expectancies were statistically significantly related to career interest. These results indicate that self-efficacy is a significant predictor of career interest, when controlling for the influence of outcome expectancies. These results also indicate that outcome expectancies are a significant predictor of career interest, when controlling for 
the influence of self-efficacy. Self-efficacy also explained a significant proportion of variance in career interests scores, $R^{2}=.60, \mathrm{~F}(2,150)=112.48, \mathrm{p}<.001$.

Table 6

Coefficients from the Regression Analysis of Self-Efficacy and Outcome Expectancies ( $N$ $=153$ )

\begin{tabular}{lccc}
\hline Predictor variable & $B$ & $S E B$ & $\beta$ \\
\hline Self-Efficacy & .73 & .06 & $.71^{* * *}$ \\
Outcome Expectancies & .25 & .09 & $.14^{* *}$
\end{tabular}

${ }^{*} p<.05 ; * * p<.01 ; * * * p .001$. 


\section{CHAPTER V \\ DISCUSSION}

People who abuse substances often have difficulty obtaining services due to a reported service gap (CASA, 2001; Michalski et al., 2010; SAMHSA, 2005a). The purpose of this study was to explore the factors that are associated with helping professionals' interest in working in the substance abuse field. SSCT provided the overall theoretical framework for this study's hypotheses. SCCT's factors used in this study were self-efficacy, outcome expectations, and career interests (Lent et al., 1994). In accordance with SCCT, I hypothesized that there would be a positive relation between self-efficacy for working with people who abuse substances and interest in working with those who abuse substances. Also, I hypothesized that there would be a positive relation between outcome expectancies for working with those who abuse substances and interest in working with those who abuse substances.

A correlation analysis was performed to explore the potential relations between self-efficacy, outcome expectancies, and career interest. The correlation analysis indicated that positive relations existed self-efficacy and career interest, outcome expectancies and career interest, and self-efficacy and outcome expectancies. These correlations indicate, for example, that when individuals endorsed a high degree of selfefficacy for performing substance abuse counseling, a higher level of career interest was also endorsed. A post-hoc regression analysis was then conducted to explore the relations postulated by SCCT further. A statistically significant relation was identified between 
self-efficacy and career interests when controlling for outcome expectancies. A statistically relation was also identified between outcome expectancies and career interest when controlling for self-efficacy. The results also indicated that a stronger relation existed between self-efficacy and career interest than between outcome expectancies and career interest.

The strong relation between self-efficacy and career interest is consistent with previous research (Baldwin et al., 2006; Lent et al., 1986; Mangrum \& Spence, 2008). Various analyses reveal that self-efficacy is both highly correlated with and predictive of the degree to which individuals express interest in careers. In a study consistent with SCCT, Sniehotta et al. (2005) examined how self-efficacy and outcome expectancies related to intentions regarding physical activity. Consistent with the findings of this study, self-efficacy held a stronger predictive relation with intentions than outcome expectancies were to intentions, though both were considered to be statistically significant. Lent et al.'s (1994) meta-analysis of self-efficacy, outcome expectancies, and interest also found self-efficacy and interest to have a stronger relation than outcome expectancies and interest.

Additionally, this study examined the impact of stigma on the relations postulated in SCCT. Therefore, I hypothesized that when counselors held strong stigma towards those who abuse substances, the relation between interest and self-efficacy would be very weak. I also hypothesized that when counselors held strong stigma towards those who abuse substances, the relation between outcome expectancies and interest would be very weak. As stated earlier, these hypotheses intended to explore if the negative beliefs held towards those who abuse substances would significantly influence career interests despite 
counselors believing they can effectively perform substance abuse counseling or holding positive beliefs regarding the consequences of performing substance abuse counseling. For counselors who did not hold strong stigma towards people who abuse substances, the relations between efficacy and interest and between outcome expectancies and interest would be positive and very strong.

A multiple regression analysis was performed to explore the relation between self-efficacy and stigma. The results of the regression indicated that stigma had no predictive relation to career interest when controlling for self-efficacy or (in a separate analysis) when controlling for outcome expectancies. The regression also indicated no significant interactions occurring between self-efficacy or outcome expectancies and stigma.

The hypotheses that stigma would weaken the relation between self-efficacy and career interests and the relation between outcome expectancies and career interests were therefore unsupported. Prior to this study, there was no published literature that explored how stigma may impact relations among SCCT-derived variables. An extensive body of research exists in regards to the role and impact that clinician stigma plays in both treatment planning and overall treatment effectiveness (Gassman \& Weisner, 2005; Luoma et al., 2007; Scott \& Wahl, 2011). Additionally, Mangrum and Spence (2008) used the SCCT framework to explore group differences in mental health and substance abuse counselors. This analysis represents an effort to unify a likely complicated and rich connection between these separate research areas.

As proposed in Luoma et al. (2007) stigma is a multifaceted construct. It is possible that none or only some facets of stigma impact the self-efficacy and interest 
relation and the outcome expectancies and interest relation. Both self-efficacy and outcome expectancies focus on appraisals related to oneself, including perception of abilities and consequences following an action. In the context of this study, stigma was a negative appraisal of others due to substance abuse issues. Stigma may have no significant impact on SCCT's postulated relations due to those relations existing based on internal appraisals of effects on oneself, and this study examined stigma as an outside appraisal. Another factor to consider in thinking about the nonsignificant role of stigma is the specialized education and training received by the clinicians participating in this study. Generally in the course of a clinician's career, he or she receives instruction in managing personal reactions towards clients while still maintaining an effective therapeutic demeanor. Based on all this training and the expectations placed on counselors to be unbiased, social desirability likely influenced the impact of stigma in clinician career decision-making. It may also account for the lack of support for the interactions originally hypothesized in this study.

\section{Limitations and Future Research}

An important aspect to scientific research is the measurement instruments used to collect data. As reported in Chapter III, the outcome expectancies measure had a sufficient alpha once the reverse-scored items were removed. This measure was developed by this researcher. The internal consistency of the measure was not tested prior to gathering data for the study. Analysis revealed that the self-efficacy and interest relation was stronger than the outcome expectancies and interest relation. This result could be partly attributed to the outcome expectancies measure only having sufficient internal consistency, as opposed to high internal consistency. Though as noted earlier, 
this finding is consistent with previous research (Lent et al., 1994; Mangrum \& Spence, 2008)

The outcome expectancies measure was created in congruence with previous outcome expectancies measures, utilizing a Likert scale with both positive and negative consequences related to behavior engagement (Smith \& Fouad, 1999; Sniehotta et al. 2005). However, in this study, the self-efficacy measure and career interest measure utilized the same structure and covered the same content domain, whereas the outcome expectancies measure utilized a stem phrase followed by a list of consequences. Future research could benefit from utilizing a different approach for the outcome expectancies measure. For example, future research would benefit from the development of a measure with higher internal consistency. Internal consistency testing prior to data collection via a pilot study would ensure more reliable data in the primary study. Also, developing an outcome expectancies measure that utilizes a similar structure to the interest and selfefficacy measure could provide more consistency in the respondents' responses.

Measurement limitations regarding stigma also may have occurred. As mentioned previously, social desirability may have limited respondents' reported levels of stigma. During the course of the study, a few respondents spontaneously reported confusion regarding accurate responses due to the measure not reflecting their personal viewpoints. Due to the PSAS only assessing for one facet of stigma, the researcher's intended facet may not have been measured by this scale (Luoma et al., 2010). Additionally, the scale's phrasing may have impacted the respondents' responses. The PSAS asks respondents to rate their responses based on question stems that state "most people..." (Luoma et al., 2007). A few spontaneous, unsolicited emails were sent during the course of the study by 
respondents who reported some confusion regarding whether to complete this scale based on their personal viewpoint or their viewpoint of how most people feel. Future studies may benefit from using a different scale or potentially develop a new scale in order to measure the respondents' personal stigma beliefs regarding substance abuse treatment more accurately.

A methodological decision when developing this study was to sample participants who provided counseling in a helping profession. This allowed the research to reflect beliefs and decisions from individuals who had already participated in career decisionmaking. These individuals are considered to be in the either the establishment or maintenance stages according to Super's life-stage theory (Swanson \& Fouad, 2010). However, utilizing students who have not yet committed to a career would provide a greater wealth of information to be gathered due to students potentially being at a stage in life in which they will be making these decisions. Super's life-stage theory indicates that students are in the exploration stage of their career development (Swanson \& Fouad, 2010). Students may hold more malleable beliefs regarding career options and societal roles. Students may also hold more undetermined beliefs regarding their self-efficacy and outcome expectancies regarding substance abuse treatment. Future research could incorporate the student population into a similar research study. This study resulted in a very high predictive relation between self-efficacy and career interest and a significant predictive relation between outcome expectancies and career interest. Sampling students, who are in the exploration stage, may demonstrate weaker relations. Along with potentially weaker relations between self-efficacy and career interest and outcome 
expectancies and career interest, it is possible that stigma may have a more influential role and could potentially serve to further weaken the postulated SCCT relations.

\section{Implications}

This study's primary purpose centered on the treatment gap that exists when individuals seek substance abuse treatment. Individuals with substance abuse concerns represent one of the primary problems that lead to individuals seeking counseling (SAMHSA, 2009; WHO, 2010). However, millions of potential clients report difficulties obtaining services (CASA, 2001; SAMHSA, 2009). Also, substance abuse concerns are often treated as a secondary concern, despite the high prevalence of these issues (Michalski et al., 2010). The apparent treatment gap for this high-prevalence client concern therefore has important implications for both current and future counselors, as well as implications regarding education and training.

The results of this study indicate that when high levels of self-efficacy are present, then career interest in substance abuse treatment is higher. Also, when high levels of positive outcome expectancies regarding substance abuse treatment are present, then career interest in substance abuse treatment is higher. These findings provide important implications regarding education and training for current and future professionals in the counseling field. Self-efficacy research suggests numerous methods by which selfefficacy beliefs can be increased (Bandura, 1977; Bandura et al., 1982). These methods combined with the reciprocal nature of the self-efficacy and career interest relation provide helpful insights for developing greater career interest in substance abuse counseling (Nauta et al., 2002). 
Career development for counselors is incredibly important due to its connection to the availability of treatment options and quality of counseling provided to clients. To close this treatment gap, higher-education and training programs would benefit from focusing on increasing self-efficacy and developing positive outcome expectancies related to substance abuse treatment amongst professionals. Based on previous findings and this study (Lent et al., 1994; Mangrum \& Spence, 2008), it may be more beneficial to focus interventions towards increasing self-efficacy beliefs due to its stronger relation with career interests. One method of increasing self-efficacy regarding substance abuse counseling could be to increase the number of classes and trainings that clinicians attend. Graduate training programs could provide a greater focus on substance abuse counseling in their training programs. Graduate programs could help foster positive outcome expectancies and increase self-efficacy simultaneously by decreasing the separation when defining treatment for substance abuse and mental health problem areas. One possibility would be combining specific substance abuse and mental health treatment techniques into a single course heading, as opposed to presenting substance abuse in a separate course. Focusing on these constructs would likely increase the number of professionals working in the substance abuse treatment field. By increasing the number of professionals working in this field, a currently underserved population will receive better treatment. By improving treatment options and quality, this will reduce the devastating effects experienced by those who struggle with substance abuse issues.

This study also serves as further supportive evidence of SCCT, as both outcome expectancies and self-efficacy were found to be predictive of career interests. Theoretically, this study adds to the literature examining outcome expectancies and 
career interests, which as reported by Lent et al. (2002) has received less attention in the research community. One of this study's findings was that self-efficacy showed a stronger predictive link to career interests than outcome expectancies in regards to substance abuse treatment. This finding has not been readily reported in previous research and serves as a useful extension of our understanding of SCCT. 


\section{REFERENCES}

Ahern, J., Stuber, J., \& Galea, S. (2007). Stigma, discrimination, and the health of illicit drug users. Drug and Alcohol Dependence, 88, 188-196.

American Psychiatric Association. (2013). Diagnostic and statistical manual of mental disorders (5th ed.). Arlington: Author.

Baldwin, A. S., Rothman, A. J., Hertel, A. W., Linde, J. A., Jeffery, R. W., Finch, E. A., \& Lando, H. A. (2006). Specifying the determinants of the initiation and maintenance of behavior change: An examination of self-efficacy, satisfaction, and smoking cessation. Health Psychology, 25, 626-634.

Bandura, A. (1977). Self-efficacy: Toward a unifying theory of behavioral change, Psychological Review, 84, 191-215. doi: 10.1037/0033-295X.84.2.191

Bandura, A. (1986). Social foundations of thought and action: A social cognitive theory. Englewood, NJ: Prentice-Hall.

Bandura, A. (1997). Self-efficacy: The exercise of control USA: W.H. Freeman and Co.

Bandura A., Reese L., \& Adams N. E (1982). Microanalysis of action and fear arousal as a function of differential levels of perceived self-efficacy. Journal of Personality and Social Psychology, 43, 5-21. doi: 10.1037/0022-3514.43.1.5

Beschner, G. M. \& Walters, J. M. (1985). Just another habit? The heroin users' perspective on treatment. In B. Hanson, G. Beschner, J. M. Walters, \& E. Bovelle (Eds.), Life with heroin: Voices from the inner city. Lexington, MA: Lexington Books.

Center for Disease Control, Department of Health and Human Service, 2002. Policy issues and challenges in substance abuse treatment. Retrieved from http://www.cdc.gov/idu/facts/PolicyFin.pdf

Cohen, J. (1992). A power primer. Psychological Bulletin, 112, 155-159. doi: 10.1037/0033-2909.112.1.155

Corrigan, P. W., Watson, A. C., \& Miller, F. E. (2006). Blame, shame and contamination: The impact of mental illness and drug dependence stigma on family members. Journal of Family Psychology, 20, 239-246. doi: 10.1037/0893-3200.20.2.239

Corrigan, P. W., Kuwabara, S. A., \& O'Shaughnessy, J. (2009). The public stigma of mental illness and drug addiction: Findings from a stratified random sample. Journal of Social Work, 9, 139-147. doi: 10.1177/1468017308101818

Craig, R.J. (1985). Reducing the treatment dropout rate in drug abuse programs. Journal of Substance Abuse Treatment, 2, 209-219. doi: 10.1016/0740-5472(85)90003-0

Crits-Christoph, P., Gallop, R., Temes, C. M., Woody, G., Ball, S. A., Martino, S., \& Carroll, K. M. (2009). The alliance in motivational enhancement therapy and counseling as usual for substance use problems. Journal of Consulting and Clinical Psychology, 77, 1125-1135. doi: 10.1037/a0017045 
Gassman, R. A., \& Weisner, C. (2005). Community providers' views of alcohol and drug problems. Journal of Social Work Practice in the Addictions, 5, 101-115. doi: 10.1300/J160v05n04 07

Hackett, G., \& Betz, N. E. (1981). A self-efficacy approach to the career development of women. Journal of Vocational Behavior, 18, 326-339. doi: 10.1016/00018791(81)90019-1

Leigh, B.C., \& Stacy, A.W. (1993). Alcohol outcome expectancies: Scale construction and predictive utility in higher order confirmatory models. Psychological Assessment, 5(2), 216-229. doi: 10.1037/1040-3590.5.2.216

Lent, R. W., Brown, S. D., \& Hackett, G. (1994). Toward a unifying social cognitive theory of career and academic interest, choice, and performance. Journal of Vocational Behavior, 45, 79-122. doi: 10.1006/jvbe.1994.1027

Lent, R. W., Brown, S. D., \& Hackett, G. (2002). Social cognitive career theory. In D. Brown (Ed), Career choice and development $4^{\text {th }}$ ed. (pp. 255- 311). San Franciso, CA: Jossey-Bass.

Lent, R. W., Brown, S. D., \& Larkin, K.C. (1986). Self-efficacy in the prediction of academic performance and perceived career options. Journal of Counseling Psychology, 33, 265-269. doi: 10.1037/0022-0167.33.3.265

Lent, R. W, Brown, S. D, Talleyrand, R., McPartland, E. B., Davis, T., Chopra, S.B., Alexander, M.S., Suthakaran, V., \& Chai, C.M. (2002). Career choice barriers, supports, and coping strategies: College students' experiences. Journal of Vocational Behavior, 60, 61-72. doi: 10.1006/jvbe.2001.1814

Link, B. G., Yang, L. H., Phelan, J. C., \& Collins, P. Y. (2004). Measuring mental illness stigma. Schizophrenia Bulletin, 30, 511-541. doi:

10.1093/oxfordjournals.schbul.a007098

Luoma, J. B., Twohig, M. P., Waltz, T., Hayes, S. C., Roget, N., Padilla, M., \& Fisher, G. (2007). An investigation of stigma in individuals receiving treatment for substance abuse. Addictive Behaviors, 32, 1331-1346. doi: 10.1016/j.addbeh.2006.09.008

Luoma, J. B., O’Hair, A. K., Kohlenberg, B. S., Hayes, S. C., \& Fletcher, L. (2010). The development and psychometric properties of a new measure of perceived stigma toward substance users. Substance Use \& Misuse, 45, 47-57. doi: $10.3109 / 10826080902864712$

Mangrum, L. F., \& Spence, R. T. (2008). Counselor and client characteristics in mental health versus substance abuse treatment settings providing services for cooccurring disorders. Community Mental Health Journal, 44, 155-169. doi: 10.1007/s10597-007-9119-2

McLaughlin, D., \& Long, A. (1996). An extended literature review of health professionals' perceptions of illicit drugs and their clients who use them. Journal of Psychiatric and Mental Health Nursing, 3, 283-288.

Michalski, D., Mulvey, T., \& Kohout, J., APA Center for Workforce Studies. 2008 APA survey of psychology health care providers. Washington DC, 2010.

Miller, W. R., \& Rose, G. S. (2009). Toward a theory of motivational interviewing. American Psychology, 64, 527-537. doi:10.1037/a0016830. 
Najavits, L. M., \& Weiss, R. D. (1994), Variations in therapist effectiveness in the treatment of patients with substance use disorders: an empirical review. Addiction, 89, 679-688. doi: 10.1111/j.1360-0443.1994.tb00954.x

Najavits, L. M., Griffin, M. L., Luborsky, L., Frank, A., Weiss, R. D., Liese, B. S., Thompson, H., Nakayama, E., Siqueland, L., Daley, D., \& Onken, L. S. (1995). Therapists' emotional reactions to substance abusers: A new questionnaire and initial findings. Psychotherapy 32, 669-677. doi: 10.1037/0033-3204.32.4.669

National Center on Addiction and Substance Abuse (2001). Shoveling up: The impact of substance abuse on state budgets. New York City, NY.

Nauta, M. M., Kahn, J. H., Angell, J. W., \& Cantarelli, E. A. (2002). Identifying the antecedent in the relation between career interests and self-efficacy: Is it one, the other, or both? Journal of Counseling Psychology, 49, 290-301. doi: 10.1037/0022-0167.49.3.290

Prochaska, J. O., \& Velicer, W. F. (1997). The transtheoretical model of health behavior change. American Journal of Health Promotion, 12, 38-48. doi: 10.4278/08901171-12.1.38

Scott, M. C., \& Wahl, O. F. (2011). Substance abuse stigma and discrimination among African-American male substance users. Stigma Research and Action, 1, 60-66. doi: 10.5463/SRA.v1i1.3

Servais, L. M., \& Saunders, S. M. (2007). Clinical psychologists' perceptions of persons with mental illness. Professional Psychology: Research and Practice, 38, $214-$ 219. doi: 10.1037/0735-7028.38.2.214

Smith, P. L., \& Fouad, N. A. (1999). Subject-matter specificity of self-efficacy, outcome expectancies, interests, and goals: Implications for the social-cognitive model. Journal of Counseling Psychology, 46, 461-471. doi: 10.1037/00220167.46.4.461

Sniehotta, F. F., Scholz, U., \& Schwarzer, R. (2005). Bridging the intention-behavior gap: Planning, self-efficacy, and action control in the adoption and maintenance of physical exercise. Psychology and Health, 20, 143-160. doi: $10.1080 / 08870440512331317670$

Substance Abuse and Mental Health Services Administration, Office of Applied Studies (2002). National and State Estimates of the Drug Abuse Treatment Gap: 2000 National Household Survey on Drug Abuse, NHSDA Series H-14, DHHS Publication No. SMA 02-3640. Rockville, MD.

Substance Abuse and Mental Health Services Administration, Office of Applied Studies (2005a). Results from the 2004 National Survey on Drug Use and Health: National Findings, NSDUH Series H-28, DHHS Publication No. SMA 05-4062. Rockville, MD.

Substance Abuse and Mental Health Services Administration, Center for Substance Abuse Treatment (2005b). Substance Abuse Treatment: Group Therapy, Treatment Improvement Protocol (TIP) Series, No. 41, 5 Stages of Treatment, Rockville, MD.

Substance Abuse and Mental Health Services Administration, Office of Applied Studies (2009). Treatment Episode Data Set (TEDS): 1997-2007. National Admissions to Substance Abuse Treatment Services, DASIS Series: S-47, DHHS Publication No. (SMA) 09-4379, Rockville, MD. 
Swanson, J. L., \& Fouad, N. A., (2010). Career theory and practice: Learning through case studies $\left(2^{\text {nd }}\right.$ ed.). Thousand Oaks, CA: SAGE Publications.

White, W. (2009). Long-term strategies to reduce the stigma attached to addiction, treatment, and recovery within the City of Philadelphia (with particular reference to medication-assisted treatment/recovery). Philadelphia, PA: Department of Behavioral Health and Mental Retardation Services.

World Health Organization (1993). International Statistical Classification of Diseases and Health Related Problems. Geneva, Switzerland: World Health Organization.

World Health Organization (2010). World Health Statistics. Retrieved from http:/www.who.int/whosis/whostat/2010/en/

Yalom, I. D., \& Leszcz, M. (2005). Specialized therapy groups. In The theory and practice of group psychotherapy (pp. 475-524). New York, NY: Basic Books. 
APPENDIX A

\section{INTEREST QUESTIONNAIRE}

Please indicate your level of interest for working with each of the following client concerns on a 1 to 5 ratings scale.

$1-$ 2 3 4 5

No Interest Moderate Interest Strong Interest

Abuse (Adult Survivors)

Academic Achievement

Addictions

Alcohol Abuse

Anger

Anxiety

Autism

Borderline Personality Disorder (BPD)

Cancer

Career Development

Child Abuse

College Student Development

Coping Behavior

Decision-Making

Depression

Developmental Issues

Drug abuse

Eating Disorders

Ethnic/Racial Identity

Gender Roles/Identity

Grief \& Loss

HIV/AIDS

Marital Conflict

Obsessive Compulsive Disorder (OCD)

Parent-Child Relationships

Perfectionism

Posttraumatic Stress Disorder (PTSD)

Religion/Spirituality/Values

Romantic Relationship Concerns

Schizophrenia 


\section{Self-Esteem}

Sexual Abuse (child victims)

Sexual Preference Issues

Stress

Substance Abuse

Suicide

Trauma

Victimization/Incest/Rape 


\section{APPENDIX B}

\section{SELF-EFFICACY MEASURE}

Please indicate your confidence for delivering effective counseling with each of the following client concerns on a 1 to 5 ratings scale.

1 No Confidence 2 Moderate Confidence 4 - 5 - 5 - 5 trong Confidence

_Abuse (Adult Survivors)

Academic Achievement

Addictions

Alcohol Abuse

Anger

Anxiety

Autism

Borderline Personality Disorder (BPD)

Cancer

Career Development

Child Abuse

College Student Development

Coping Behavior

Decision-Making

Depression

Developmental Issues

Drug abuse

Eating Disorders

Ethnic/Racial Identity

Gender Roles/Identity

Grief \& Loss

HIV/AIDS

Marital Conflict

Obsessive Compulsive Disorder (OCD)

Parent-Child Relationships

Perfectionism

Posttraumatic Stress Disorder (PTSD)

Religion/Spirituality/Values

Romantic Relationship Concerns

Schizophrenia 


\section{Self-Esteem}

Sexual Abuse (child victims)

Sexual Preference Issues

Stress

Substance Abuse

Suicide

Trauma

Victimization/Incest/Rape 


\section{APPENDIX C \\ OUTCOME EXPECTANCIES MEASURE}

Please indicate your agreement for consequences related to working with individuals who abuse substances on a 1 to 5 ratings scale.

1 ---------- 2 ----------- 3 ------------ 4 ----------- 5

By working with individuals who abuse substances...

1....I will help to solve a prevalent social problem.

2. ...I can provide services to an under-treated population.

3. ...my career opportunities will be limited.

4. ...my colleagues will respect me more.

5. ...I will make less money.

6. ...there will be minimal satisfaction from working with this population.

7. ...my therapeutic skills will become more diversified.

8. ... I well get little appreciation from the clients.

9. ...I will face difficult work that requires outside training/supervision/consultation.

$10 . .$. I will help to reduce crime and recidivism 


\section{APPENDIX D}

\section{DEMOGRAPHIC ITEMS}

1. Sex: _ Male _ Female

2. Highest Degree Achieved:
Ph.D.
Psy.D.
M.S./M.A./M.SW.
B.S./B.A. Other

3. Ethnicity: African-American Native American Hispanic Origins Asian or Asian American White Caucasian Other (specify : Biracial or multiracial

4. How many years have you been a practicing mental health professional? Years Months

5. Are you currently a licensed mental health professional? _ Yes__ No (go to question 7)

6. If yes, in what discipline/field are you licensed? (check all that apply)

$\begin{array}{ll}\text { Psychology } & \text { Social Work } \\ \text { Counseling } & \text { Medicine } \\ \text { Family Therapy } & \text { O Other (specify : }\end{array}$

7. Please select your major theoretical orientation (check only one):

Behavioral
Eclectic
Humanistic/Existential
Psychodynamic
Cognitive
Family Systems
Other (specify

8. Check the primary setting in which you practice: Community Mental Health Center General Medical Center Psychiatric Medical Center Private or Group Practice Child/Pediatric Medical Center Child/Adolescent/Family Guidance Center University Counseling Center VA Medical Center 
Other (specify :

) 


\section{APPENDIX E \\ SERVICE-LOAD MEASURE}

Estimate the amount of time descriptively that you rendered services over the past 60 days to the following client concerns on a 1 to 5 ratings scale:

1 None $\quad$ Rarely $\quad$ Some 3 Very Often

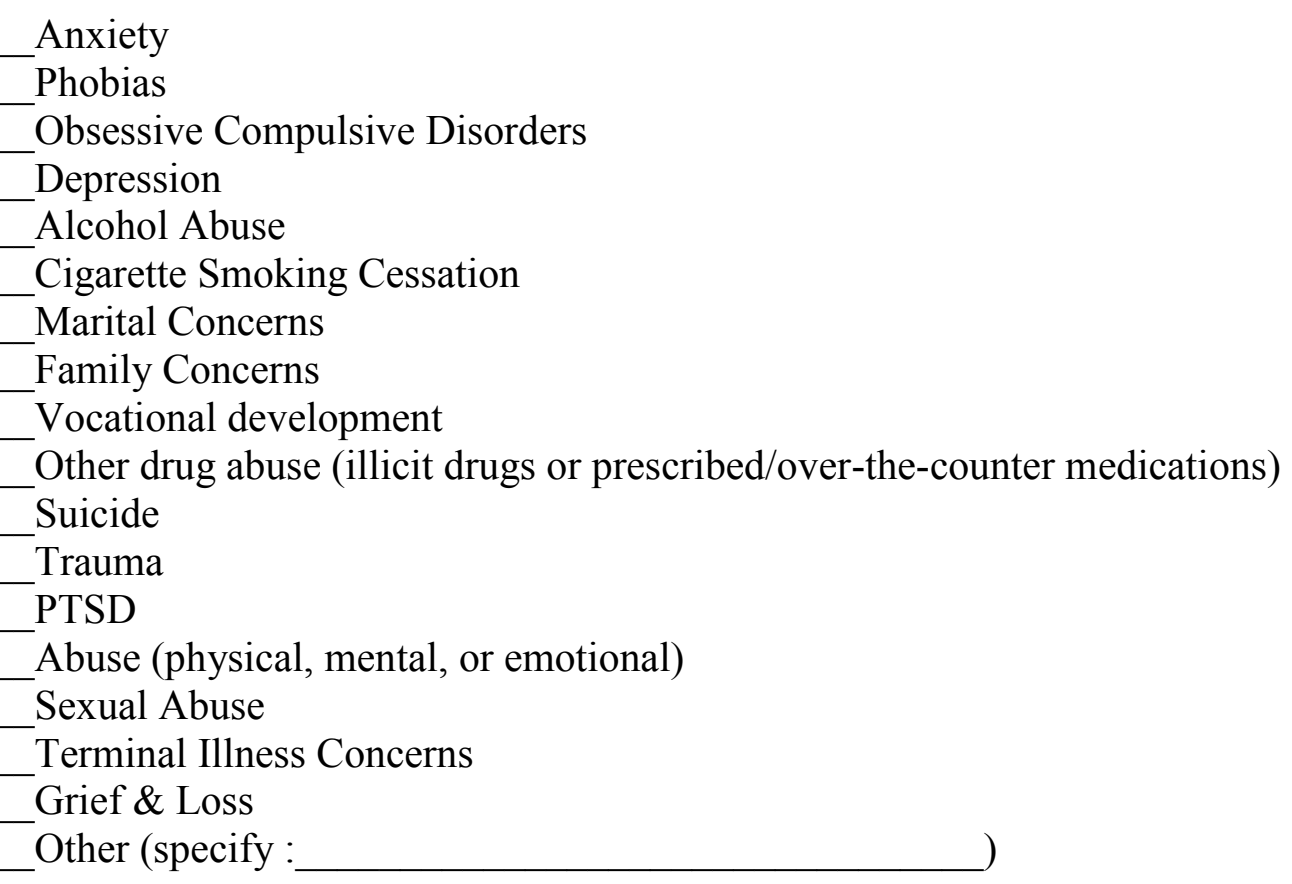




\section{APPENDIX F \\ RECRUITMENT EMAIL}

Dear licensed counselor,

I would like to invite you to participate in a brief study looking at licensed counselors' career interests. I, and others, have explored the factors that contribute to career interests. It is especially important to explore the career interests of counselors, due to the variety of services needed by the general population. By reporting your career interests, it helps determine factors relevant to career interests within the counseling field.

We know that your time is extremely valuable and that mine may not be the first research project you have been asked to complete this year. Therefore, we have designed this study to take as little time as possible and to be convenient for you. The survey is available on-line and should take you 10 minutes to complete. After completing this questionnaire you will have the option of entering your name into a raffle prize to win a \$25 gift card.

Your privacy is important to me, and your survey responses will be kept confidential. You will not place your name on the survey.

Benefits to completing this survey include being able to contribute to the literature on career interests of licensed counselors. Ideally the results of this study will be used to help explore factors that contribute to the career interests of counselors.

To participate in this survey simply click on the survey link below and follow the onscreen instructions. I will be happy to answer any questions that you have. Just address them to gacover@chestnut.org. Thank you in advance for time and input in this study.

\section{To take the survey click on the following link: $<$ Survey link $>$}

Sincerely,

Genevieve Covert, MS Candidate 


\title{
APPENDIX G
}

\section{INFORMED CONSENT DOCUMENT}

\author{
Illinois State University \\ Department of Psychology (2013) \\ Informed Consent for Participants
}

Study Name:

Clinician interests in working

in substance abuse: the role

of self-efficacy, outcome

expectancies, \& stigma
Principal Investigator:

Genevieve Covert
Faculty Supervisor:

Jeffrey Kahn

PLEASE READ THIS DOCUMENT CAREFULLY. YOUR SIGNATURE IS REQUIRED FOR PARTICIPATION. YOU MUST BE AT LEAST 18 YEARS OF AGE TO GIVE YOUR CONSENT TO PARTICIPATE IN RESEARCH. IF YOU DESIRE A COPY OF THIS CONSENT FORM, YOU MAY REQUEST ONE AND WE WILL PROVIDE IT.

The policy of the Department of Psychology is that all research participation in the Department is voluntary, and you have the right to withdraw at any time, without prejudice, should you object to the nature of the research. You are entitled to ask questions and to receive an explanation after your participation.

\section{Description of the Study:}

This is a single response survey in which a number of surveys are provided, asking for your responses. Most of the surveys utilize Likert scales for proper responses.

\section{Nature of Participation:}

You will participate in completing a set of four online surveys, taking approximately ten minutes to complete in their entirety.

\section{Purpose of the Study:}

To evaluate career decisions of current licensed counselors. This means we want to find out some general information about the career interests and degree of confidence licensed counselors have in regards to various areas of counseling as well as to gather some general perceptions that licensed counselors have in regards to clients. We are only interested in an evaluation of these variables, and how they are related to one another. We are NOT interested in any specific individual.

\section{Possible Risks:}

a) When filling out questionnaires, you may come across a question or answer choice that you find unpleasant, upsetting, or otherwise objectionable.

b) For the questionnaires we are evaluating, there is no right or wrong answers. It is to be expected that there will be variations in the responses received by different participants. 
c) You will be asked to provide confidential information about yourself.

\section{Possible Benefits:}

a) When your participation is complete, you will be given an opportunity to learn about this research, which may be useful to you in understanding yourself and others.

b) You will have an opportunity to contribute to psychological science by participating in this research.

\section{Compensation for your Time:}

If you choose, you will be entered into a drawing to win a $\$ 25$ gift card; you are free to withdraw your participation at any time without penalty.

\section{Confidentiality:}

Your responses will be anonymous, your name is not requested and will not appear on any of the questionnaires. No one will be able to know which are your questionnaire responses. Finally, remember that it is no individual person's responses that interest us.

\section{Opportunities to Question:}

Any technical questions about this research may be directed to:

Principal Investigator:

Genevieve Covert

Phone: $\underline{309-706-}$ 9628

Any questions regarding your rights as a research participant or research-related injuries may be directed to ISU's Office of Research, Ethics, and Compliance, (309) 438-2520.

\section{Opportunities to Withdraw at will:}

If you decide now or at any point to withdraw this consent or stop participating, you are free to do so at no penalty to yourself. You are free to skip specific questions and continue participating at no penalty.

Opportunities to be Informed of Results:

In all likelihood, the results will be fully available around May of 2014. Preliminary results will be available earlier. If you wish to be told the results of this research, please contact:

\section{Principal Investigator: Genevieve Covert}

Phone:_309-706$\underline{9628}$

$\mathrm{He} / \mathrm{she}$ will either meet with you or direct you to where you can read a copy of the results. In addition, there is a chance that the results from this study will be published in a scientific psychology journal, which would be available in many libraries.

Click "Next" if you agree to participate. 


\section{APPENDIX H}

\section{STUDY DEBRIEFING}

This study is concerned with the factors that impact clinicians' interests in working in substance abuse counseling. This study utilized the Social Cognitive Career Theory, focusing on self-efficacy, outcome expectancies, and interests. This study also assessed for stigma towards working with individuals who abuse substances, as a moderating variable that impacts interests.

In this study, you were asked to complete a series of questionnaires, using Likert scales to indicate your responses. The responses were then either averaged or summed up to determine self-efficacy, outcomes expectancies, degree of stigma, and interest in regards to substance abuse counseling and people who abuse substances.

I expect to find that self-efficacy and interest in working in substance abuse counseling have a positive relationship. I also expect to find that outcome expectancies and interest in working in substance abuse counseling have a positive relationship. When a clinician has a high degree of self-efficacy or positive outcome expectancy, they have a higher degree of interest in substance abuse counseling.

I also expect to find that stigma is a moderating variable that influences clinicians' degree of interest in substance abuse counseling. This means that even when a clinician reports a high degree of self-efficacy for performing substance abuse counseling, if they also hold a high degree of stigma towards working with those who abuse substances, their interest in substance abuse counseling is low. Also, a clinician will positive outcome expectancy will experience lower interest levels for substance abuse counseling if they have a high degree of stigma towards those who abuse substances.

There is established research for Social Cognitive Career Theory; however, there is limited research into the potential moderating role that stigma has on career interests. Also, the research suggests that those who abuse substances are an under-treated population; it is important to explore if a lack of career interest by clinicians is related to the limited access to counseling resources that individuals who abuse substances often encounter.

If you are interested in learning more about the study and the role that stigma plays in clinician interests for substance abuse counseling or if you would like to receive a report of this research when it is completed (or a summary of the findings), please contact Genevieve Covert at covertg87@gmail.com or 309-706-9628. 
If you have concerns about your rights as a participant in this experiment, please contact the ISU IRB Assistant Director of Research Ethics and Compliance Kathy Spence at (309) 438-2520.

Thank you again for your participation. 